\title{
Contribuições do design para as smart cities
}

Daros, Carolina; Doutoranda; Universidade Federal do Paraná carolinadaros@gmail.com

Kistmann, Virginia Borges; Doutora; Universidade Federal do Paraná vkistmann@ufpr.br

Zaina, Tatiana Zimermann; Mestranda; Universidade Federal do Paraná tatizimermann\#@gmail.com

Resumo: O presente artigo apresenta um estudo teórico sobre o conceito de Smart City $(\mathrm{SC})$ relacionado à gestão de design. Para isso, parte da definição do termo SC identificando as áreas pertinentes às aplicações dessa abordagem. A seguir, estabelece as possíveis relações com o design de modo abrangente. $\mathrm{O}$ artigo se fundamenta em uma pesquisa baseada em revisão de literatura integrativa, a qual buscou consolidar as definições e abordagens encontradas através de tendências globais comuns. Os resultados apontam as potenciais áreas de atuação do designer no âmbito desta temática.

Palavras-chave: smart city, cidades inteligentes, gestão de design.

\begin{abstract}
This paper presents a theoretical study about the concept of Smart City (SC) related to design. It starts with the definition of SC, and it is described briefly the relevant applications of this approach areas. The following sets out the possible relations with the design comprehensively. This paper is based on integrative literature rewiew, which sought to consolidate the definitions and approaches found through common global trends. The results indicate the potential areas of the designer within this thematic.
\end{abstract}

Key-words: smart city, design management.

\section{INTRODUÇÃO}

Os últimos anos foram marcados por intensas mudanças nos territórios e o século XXI, possivelmente, por esta razão será denominado como o século das cidades (CELEBREIROS E GULÍN, 2014). Essa afirmação pode ser corroborada com as projeções da Organização das Nações Unidas (ONU, 2012) que estimam que as populações urbanas crescerão em mais de 2 bilhões de pessoas nos próximos 40 anos. Assim, a população mundial ultrapassará os 9 bilhões de habitantes e desta população, 65\% estarão vivendo em cidades em 2050 (ONU, 2012).

Ao que se refere as cidades da América Latina e Caribe constata-se que são as regiões mais urbanizadas do mundo embora menos povoadas em relação ao seu território, aproximadamente $80 \%$ de sua população vive em cidades. Esse percentual é 
considerado superior quando comparado ao do grupo de países desenvolvidos (ONU HABITAT, 2012).

No caso do Brasil, o processo de urbanização aconteceu rapidamente em algumas metrópoles e as consequências disso pode ser observada em problemas sociais, econômicos, ambientais e organizacionais. Tais problemas comprometem a funcionalidade das cidades em diversas áreas: dificuldade na gestão de resíduos, escassez e má gestão de recursos, poluição, condições inadequadas no sistema de saúde, precariedade de transporte e mobilidade, inadequação e obsolescência das infraestruturas e carências nas atividades de segurança pública, bem como outras restrições que prejudicam a qualidade de vida da população (TOPPETA, 2010)

Esses problemas exigem atenção e representam grandes desafios aos governos, considerando que cabe ao poder público o atendimento às demandas por serviços adequados aos cidadãos, bem como novas abordagens para planejamento, projeto, financiamento, gestão e operação de infraestruturas urbanas (BOYKO, 2006; HARRISON; DONNELLY, 2011; RASOOLIMANESH et al., 2011).

Portanto, refletir e discutir a temática cidades torna-se relevante, especialmente quando têm-se dados tão representativos como o crescimento urbano, as demandas por soluções criativas, inovadoras e inclusivas. Na literatura é possível encontrar diferentes expressões que buscam denominar as solução para os problemas complexos das cidades, como por exemplo: cidades inovadoras, cidades sustentáveis, cidades criativas, cidades digitais, cidades globais, e mais recentemente Smart City (SC) ou cidades inteligentes ${ }^{1}$.

Optou-se por compreender melhor conceito de SC, na medida em que este surge como proposição de desenvolvimento urbano inteligente e sustentável, visando a melhoria da qualidade de vida dos cidadãos. Portanto, esse artigo tem como objetivo discutir os conceitos relacionados à SC, identificar as potenciais áreas de aplicação desta abordagem e como esta temática se relaciona com o design. Desta forma, pretende-se oferecer melhor entendimento sobre o tema e como a gestão de design pode contribuir neste cenário.

O artigo aqui apresentado apoia-se na revisão integrativa da literatura. Esta metodologia de pesquisa mostrou-se útil por consistir-se da aproximação das informações coletadas tanto na revisão literatura narrativa ou tradicional, que caracteriza-se pela temática mais abrangente (CORDEIRO et al, 2007), quanto as informações coletadas pela revisão sistemática.

O presente artigo foi organizado contemplando, além desta sessão introdutória, uma sessão em que são apresentados os conceitos de SC encontrados na literatura e suas principais categorias de aplicação. Tais categorias e subcategorias são discutidas a fim de relacioná-las com a gestão de design. Por fim, são expostas as considerações finais.

\section{As definições atribuídas à $\mathrm{SC}$}

O termo cidade inteligente é uma tradução do termo inglês Smart City - SC, que, de acordo com Cebreiros e Gulín (2014), surgiu há duas décadas para tratar dos problemas de sustentabilidade com ênfase na eficiência energética e na redução das emissões de carbono relativos às cidades.

\footnotetext{
${ }^{1} \mathrm{O}$ termo smart foi traduzido como inteligente, mas em inglês o seu conceito inclui significados tais como elegante. Assim, inteligente significa não apenas ter informação, mas gerar conhecimento que signifique qualidade de vida.
} 
No entanto, o termo SC apresenta conceitos diversos de acordo com vários autores, como no quadro abaixo (QUADRO 1).

\begin{tabular}{|c|c|c|}
\hline Autor & Ano & Conceito de SC \\
\hline HALL & 2000 & $\begin{array}{l}\text { São aquelas que monitoram e integram as condições de operações de todas as } \\
\text { infraestruturas críticas da cidade, atuando de forma preventiva para a } \\
\text { continuidade de suas atividades fundamentais. }\end{array}$ \\
\hline KANTER; LITOW & 2009 & $\begin{array}{l}\text { São aquelas capazes de conectar de forma inovativa as infraestruturas físicas e de } \\
\text { TIC, de forma eficiente e eficaz, convergindo os aspectos organizacionais, } \\
\text { normativos, sociais e tecnológicos a fim de melhorar as condições de } \\
\text { sustentabilidade e de qualidade vida da população }\end{array}$ \\
\hline TOPPETA & 2010 & $\begin{array}{l}\text { São aquelas que combinam as facilidades das TIC e da Web } 2.0 \text { com os esforços } \\
\text { organizacionais, de design e planejamento, para desmaterializar e acelerar os } \\
\text { processos burocráticos, ajudando a identificar e implementar soluções inovadoras } \\
\text { para o gerenciamento da complexidade das cidades. }\end{array}$ \\
\hline GIFFINGER; GUDRUN & 2010 & $\begin{array}{l}\text { São aquelas que bem realizam a visão de futuro em várias vertentes - economia, } \\
\text { pessoas, governança, mobilidade, meio ambiente e qualidade de vida -, e são } \\
\text { construídas sobre a combinação inteligente de atitudes decisivas, independentes e } \\
\text { conscientes dos atores que nelas atuam. }\end{array}$ \\
\hline WASHBURN et al. & 2010 & $\begin{array}{l}\text { São aquelas que usam tecnologias de smart computing para tornar os } \\
\text { componentes das infraestruturas e serviços críticos - os quais incluem a } \\
\text { administração da cidade, educação, assistência à saúde, segurança pública, } \\
\text { edifícios, transportes e utilities - mais inteligentes, interconectados e eficientes. }\end{array}$ \\
\hline $\begin{array}{l}\text { DUTTA et al. } \\
\text { Essa abordagem é } \\
\text { acompanhada por Harrison; } \\
\text { Donnelly (2011). }\end{array}$ & 2011 & $\begin{array}{l}\text { As cidades inteligentes têm foco em um modelo particularizado, com visão } \\
\text { moderna do desenvolvimento urbano e que reconhecem a crescente importância } \\
\text { das TICs no direcionamento da competitividade econômica, sustentabilidade } \\
\text { ambiental e qualidade de vida geral. }\end{array}$ \\
\hline $\begin{array}{l}\text { SCHAFFERS et al., 2011; } \\
\text { HERNÁNDEZ- MUÑOZ } \text { et al., } \\
\text { 2011; CHOURABI, 2012; } \\
\text { CADENA; DOBBS; REMES, 2012 }\end{array}$ & & $\begin{array}{l}\text { São aquelas que reconhecem a importância e se utilizam das TICs para alavancar } \\
\text { competitividade econômica, promover suporte às ações de gestão ambiental e } \\
\text { proporcionar melhoria da qualidade de vida dos cidadãos. }\end{array}$ \\
\hline NAM; PARDO & 2011 & $\begin{array}{l}\text { São aquelas que têm por objetivo a melhoria na qualidade dos serviços aos } \\
\text { cidadãos. }\end{array}$ \\
\hline CELEBREIROS; GULÍN & 2014 & $\begin{array}{l}\text { São aquelas que prestam serviços de um modo diferente e mais eficiente com o } \\
\text { objetivo de os poder manter e, inclusivamente, de os melhorar. }\end{array}$ \\
\hline $\begin{array}{l}\text { European Innovation } \\
\text { Partnership on Smart Cities } \\
\text { and Communities - Strategic } \\
\text { Implementation Plan }\end{array}$ & 2013 & $\begin{array}{l}\text { São sistemas de pessoas utilizando e interatuando com materiais, serviços e } \\
\text { financiamento, para catalisar um desenvolvimento econômico, sustentável, } \\
\text { resiliente e um alto nível de vida. Estas interações tornam-se smart através de } \\
\text { uma utilização estratégica das infraestruturas de informação e comunicação, em } \\
\text { um processo de planificação e gestão urbana transparente que reage perante as } \\
\text { necessidades sociais e econômicas da sociedade. }\end{array}$ \\
\hline CARAGLIU; DEL BO; NIJKAMP & 2011 & $\begin{array}{l}\text { Uma cidade inteligente se forma quando investimentos em capital humano e } \\
\text { social, tradicional (transporte) e moderna (TIC) infraestrutura tecnológica de } \\
\text { comunicação alimentam um crescimento econômico sustentável e priorizam a } \\
\text { qualidade de vida, por meio de uma gestão sábia dos recursos naturais e de uma } \\
\text { governança participativa. }\end{array}$ \\
\hline
\end{tabular}

Fonte: Elaborado pelas autoras, com base na pesquisa de Weiss et al. e pesquisa das autoras, 2013.

Nota-se que na maioria das definições apresentadas considera o uso das TICs como fator propulsor ao conceito de SC. Alguns autores, por outro lado, mencionam as TICs associada ao capital humano e a gestão participativa, ou seja, a sociedade como elemento intrínsecos à SC.

Outra característica incorporada nas TICs são as contribuições para a geração e produção de conhecimento que por consequência serão empregados em ideias, projetos ou soluções para as cidades. De acordo com a OCDE (2012), as cidades são fatores centrais da transformação, enquanto eixos da economia global, salientando o seu papel no desenvolvimento econômico baseado no talento, ou seja, as cidades concentram maior parte da população mais qualificada, formada, criativa e empreendedora (OCDE,2012), sendo assim são um terreno fértil para as inovações (LEITE, 2012). 
As inovações podem ter caráter incremental, ou radical, ou mudanças no sistema tecnológico ou revoluções tecnológicas que estão, geralmente, relacionadas a avanços das tecnologias (FREEMAN, PEREZ, 1988) que são aplicadas em produtos, processos, mercado, materiais, gestão (SCHUMPETER, 1997). Nesse contexto, as inovações tecnológicas desempenham um importante papel para desenvolvimento das cidades, principalmente quando nos referimos ao termo SC.

O outro tipo de inovação a ser considerado no contexto cidades são as inovações sociais que utilizam novas estratégias, conceitos e métodos a fim de atender as necessidades sociais das mais diversas naturezas, como por exemplo trabalho, lazer, educação, saúde, etc. Estas inovações referem-se aos processos sociais de inovação, as inovações de interesse social, como também ao empreendedorismo de interesse social como suporte da ação inovadora (BARTHOLO, 2007 in MANZINI, 2009).

As inovações sociais também possibilitam a produção de conhecimento, o desenvolvimento local e a inclusão social. No entanto, a inovação social parte da sociedade para a esfera da política, do local para o nacional e o global. Neste caso, as TICs são empregadas como ferramenta para novas experiências inovadoras, construídas a partir de novas relações sociais que se apropriam ou desenvolvem novas técnicas e metodologias participativas, esse conjunto de características compõem a Tecnologia Social (TS).

Portanto, pode-se dizer que a SC compreende o uso das TICs e TS, sendo estes componentes fundamentais para a orientação das tomadas de decisão, planejamento e gestão das cidades, de forma que estas atinjam os objetivos de otimização e uso inteligente dos recursos tangíveis (infraestrutura de transporte, energia, água) e intangíveis (capital humano, intelectual e organizacional de empresas e órgãos públicos).

Dessa forma, a gestão de design pode contribuir para o desenvolvimento das cidades contemporâneas, aproveitando-se da sua característica inovadora, associada às novas Tecnologias de Informação e Comunicação (TICS) e da Tecnologia Social (TS). Para tanto, o próximo tópico apresenta as categorias de atuação da SC.

\subsection{Categorias de atuação da Smart City}

Neirotti et al. (2014) sugerem seis categorias para implantação de SC relacionadas ao desenvolvimento urbano e a aplicação de políticas, a partir de uma classificação anterior em categorias "rígidas" e categorias "flexíveis".

Para os autores, as categorias consideradas "rígidas" são: recursos naturais e energia, transporte e mobilidade, edifícios comerciais e residenciais. Esta categoria também compreende a gestão dos recursos hídricos, solar, eólico, gestão dos resíduos, saúde e segurança pública. Os autores acreditam que uma melhora da sustentabilidade para estas categorias está diretamente relacionada a implantação de TICs, combinada com intervenções políticas de planejamento e aprimoramento urbano (NEIROTTI et al, 2014). Ou seja, as categorias rígidas são aquelas que correspondem aos elementos que configuram as cidades, são passíveis de aplicação de soluções de TICs em função do uso de sensores, tecnologias sem fio e softwares que trabalham com uma grande massa de dados (McKinsey Global de Instituto, 2011; McAfee e Brynjolfsson, 2012).

As categorias denominadas "flexíveis" são: vida e convivência, governança, economia e pessoas. Essas categorias incluem áreas como educação, cultura, políticas 
que fomentam o empreendedorismo, a inovação, a inclusão social, assim como a comunicação entre a administração pública e os cidadãos (e-governance ${ }^{2}$ ). Os autores consideram que essas categorias não dependem necessariamente das TICs no aspecto de processamento e integração de informações em tempo real.

No entanto, discorda-se desta classificação entre categorias rígidas e flexíveis, na medida em que pode-se adotar uma postura híbrida, ou seja, que inclui uma abordagem rígida e flexível ao mesmo tempo, em menor ou maior grau independente da categoria. A seguir apresenta-se o Quadro $2 \mathrm{com}$ as categorias e subcategorias de atuação na SC, propostas por Neirotti et al. (2014), com uma breve descrição de cada uma delas.

\section{Quadro 2 - Categorias e subcategorias de atuação na SC}

\begin{tabular}{|c|c|c|}
\hline $\begin{array}{l}\text { Categorias de } \\
\text { atuação }\end{array}$ & Subcategoria & Descrição \\
\hline \multirow[t]{6}{*}{$\begin{array}{l}\text { Recursos naturais e } \\
\text { energia }\end{array}$} & Smat Grids & $\begin{array}{l}\text { As redes de eletricidade capaz de levar em conta os comportamentos de } \\
\text { todos os usuários conectados a fim de empregar fontes sustentáveis, } \\
\text { econômicas e seguras de energia elétrica. As redes inteligentes devem } \\
\text { ser autossuficientes e resistente a anomalias do sistema. }\end{array}$ \\
\hline & $\begin{array}{l}\text { Iluminação } \\
\text { pública }\end{array}$ & $\begin{array}{l}\text { lluminação de espaços públicos com lâmpadas de rua que oferecem } \\
\text { diferentes funções, tais como o controle da poluição do ar e } \\
\text { conectividade Wi-Fi gratuito. Sistemas de gestão centralizada que se } \\
\text { comunicam diretamente com os postes de luz pode permitir a redução } \\
\text { dos custos de manutenção e operação, análise de informações em tempo } \\
\text { real sobre as condições meteorológicas e, consequentemente, regulagem } \\
\text { da intensidade da luz, por meio da tecnologia LED. }\end{array}$ \\
\hline & $\begin{array}{l}\text { Energia } \\
\text { renovável }\end{array}$ & $\begin{array}{l}\text { Exploração dos recursos naturais que são regenerativos ou inesgotáveis, } \\
\text { como calor, água (rios e mares) e energia eólica }\end{array}$ \\
\hline & $\begin{array}{l}\text { Gestão de } \\
\text { resíduos }\end{array}$ & $\begin{array}{l}\text { Coleta de gestão de resíduos, reciclagem e eliminação dos resíduos de } \\
\text { forma a evitar os impactos negativos de uma gestão de resíduos } \\
\text { incorreta sobre as pessoas e meio ambiente }\end{array}$ \\
\hline & $\begin{array}{l}\text { Gestão da } \\
\text { água }\end{array}$ & $\begin{array}{l}\text { Analisar a gestão da água e gestão da quantidade e qualidade da água ao } \\
\text { longo das fases do ciclo hidrológico e, em particular, quando a água é } \\
\text { utilizada para fins agrícolas, municipais e industriais }\end{array}$ \\
\hline & $\begin{array}{l}\text { Alimentação e } \\
\text { agricultura }\end{array}$ & $\begin{array}{l}\text { Redes de sensores sem fio para gerenciar as culturas e conhecer as } \\
\text { condições em que as plantas estão crescendo. Através da combinação de } \\
\text { sensores de umidade, temperatura e luz o risco de geada podem ser } \\
\text { reduzidos e doenças de plantas possíveis ou requisitos de rega com base } \\
\text { na umidade do solo pode ser detectado }\end{array}$ \\
\hline \multirow[t]{3}{*}{$\begin{array}{l}\text { Transporte e } \\
\text { mobilidade }\end{array}$} & $\begin{array}{l}\text { Logística da } \\
\text { cidade }\end{array}$ & $\begin{array}{l}\text { Melhorar fluxos logísticos nas cidades, integrando efetivamente as } \\
\text { necessidades do negócio com as condições de tráfego, geográfica e } \\
\text { questões ambientais }\end{array}$ \\
\hline & $\begin{array}{l}\text { Informações } \\
\text { de mobilidade }\end{array}$ & $\begin{array}{l}\text { Distribuição e utilização de informações selecionadas e dinâmicas dos } \\
\text { diferentes modais, tanto pré-viagem e, mais importante, durante a } \\
\text { viagem, com o objetivo de melhorar o tráfego e a eficiência de transporte } \\
\text { assegurando uma experiência de viagem de alta qualidade }\end{array}$ \\
\hline & $\begin{array}{l}\text { Mobilidade de } \\
\text { pessoas }\end{array}$ & $\begin{array}{l}\text { Formas inovadoras e sustentáveis de transporte de pessoas nas cidades, } \\
\text { tais como o desenvolvimento de modos de transporte público e veículos } \\
\text { com base em combustíveis eco-friendly e sistemas de propulsão, } \\
\text { apoiados por tecnologias avançadas e comportamentos dos cidadãos } \\
\text { proativos }\end{array}$ \\
\hline
\end{tabular}

2 E-governance: serviços de governo inteligente mais ágeis, transparentes e eficientes, pelo compartilhamento de informações (LEITE, 2004). 


\begin{tabular}{|c|c|c|}
\hline $\begin{array}{l}\text { Categorias de } \\
\text { atuação }\end{array}$ & Subcategoria & Descrição \\
\hline \multirow[t]{3}{*}{ Edifícios } & $\begin{array}{l}\text { Gestão de } \\
\text { instalação }\end{array}$ & $\begin{array}{l}\text { Limpeza e gerenciamento de instalações, manutenção, propriedade, } \\
\text { locação, tecnologia e modos de operação associados com instalações em } \\
\text { áreas urbanas serviços de construção }\end{array}$ \\
\hline & Serviços & 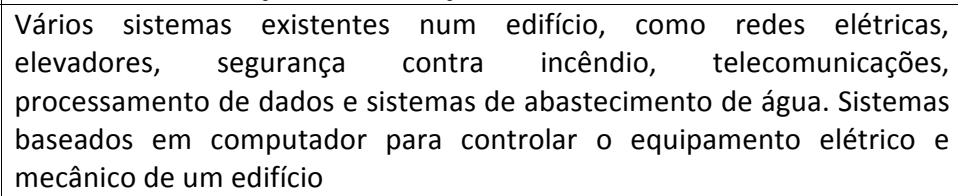 \\
\hline & $\begin{array}{l}\text { Qualidade da } \\
\text { edificação }\end{array}$ & $\begin{array}{l}\text { Aspectos relacionados à qualidade de vida em um edifício residencial, } \\
\text { tais como conforto, iluminação e aquecimento, ventilação e ar } \\
\text { condicionado. Ele inclui tudo o que corresponde ao nível de satisfação } \\
\text { das pessoas que vivem em relação ao imóvel }\end{array}$ \\
\hline \multirow[t]{7}{*}{ Vida / convivência } & $\begin{array}{l}\text { Entreteniment } \\
\text { o }\end{array}$ & $\begin{array}{l}\text { Os modos de fomentar o turismo e a prestação de informações sobre } \\
\text { eventos de entretenimento e propostas para o tempo livre e vida } \\
\text { noturna }\end{array}$ \\
\hline & Hospitalidade & $\begin{array}{l}\text { Capacidade de uma cidade para acomodar os estudantes estrangeiros, } \\
\text { turistas e outras pessoas não residentes, oferecendo soluções adequadas } \\
\text { às suas necessidades }\end{array}$ \\
\hline & $\begin{array}{l}\text { Controle de } \\
\text { poluição }\end{array}$ & $\begin{array}{l}\text { Controlar emissões e efluentes por meio de diferentes tipos de } \\
\text { dispositivos. Estimulando as decisões para melhorar a qualidade do ar, da } \\
\text { água e no ambiente em geral }\end{array}$ \\
\hline & $\begin{array}{l}\text { Segurança } \\
\text { pública }\end{array}$ & $\begin{array}{l}\text { Proteger os cidadãos e os seus bens através do envolvimento ativo das } \\
\text { organizações locais públicos, a polícia e os próprios cidadãos. Coleta e } \\
\text { monitoramento de informações para a prevenção do crime }\end{array}$ \\
\hline & Saúde & $\begin{array}{l}\text { Prevenção, diagnóstico e tratamento da doença suportada pelas TIC. } \\
\text { Garantir instalações e serviços eficientes no sistema de saúde }\end{array}$ \\
\hline & $\begin{array}{l}\text { Bem estar e } \\
\text { inclusão social }\end{array}$ & $\begin{array}{l}\text { Melhorar a qualidade de vida, estimulando a aprendizagem e a } \\
\text { participação social, com especial referência a categorias específicas de } \\
\text { cidadãos, como o mais velho e deficientes }\end{array}$ \\
\hline & Cultura & $\begin{array}{l}\text { Facilitar a difusão de informações sobre as atividades culturais e de } \\
\text { motivar as pessoas a se envolver nas atividades e projetos }\end{array}$ \\
\hline \multirow[t]{4}{*}{ Governança } & E-government & $\begin{array}{l}\text { Digitalização da administração pública através da gestão de documentos } \\
\text { e procedimentos, através de ferramentas de TIC, a fim de otimizar o } \\
\text { trabalho e oferecer serviços rápidos e novos para os cidadãos }\end{array}$ \\
\hline & E-democracia & Utilizar sistemas inovadores de TIC para apoiar a votação/eleição \\
\hline & Aquisição & $\begin{array}{l}\text { Permitir que o setor público melhore os procedimentos de aquisição e } \\
\text { gestão de contratos associados, com a finalidade de assegurar o melhor } \\
\text { valor monetário (custo-benefício), sem diminuir a qualidade }\end{array}$ \\
\hline & Transparência & $\begin{array}{l}\text { Facilitar o acesso dos cidadão aos documentos oficiais, bem como a } \\
\text { participação nos processos de decisão de um município. Diminuir a } \\
\text { possibilidade das autoridades de tirar proveito do sistema para seus } \\
\text { próprios interesses ou ocultar informações relevantes }\end{array}$ \\
\hline \multirow[t]{4}{*}{ Economia e pessoas } & $\begin{array}{l}\text { Inovação e } \\
\text { empreendedor } \\
\text { ismo }\end{array}$ & $\begin{array}{l}\text { Medidas para promover os sistemas de inovação e empreendedorismo } \\
\text { no ecossistema urbano (por exemplo, presença de incubadoras locais, } \\
\text { novos ambientes de negócios, startups, serviços financeiros, economia } \\
\text { criativa) }\end{array}$ \\
\hline & $\begin{array}{l}\text { Gestão do } \\
\text { patrimônio } \\
\text { cultural }\end{array}$ & $\begin{array}{l}\text { O uso de sistemas de TIC (por exemplo, tecnologias de realidade } \\
\text { aumentada) para a entrega de nova experiência do cliente em apreciar o } \\
\text { patrimônio cultural da cidade. Uso de sistemas de informação de gestão } \\
\text { de ativos para lidar com a manutenção de prédios históricos }\end{array}$ \\
\hline & \begin{tabular}{|l|} 
Educação \\
digital
\end{tabular} & $\begin{array}{l}\text { O uso extensivo de ferramentas modernas de TIC (por exemplo, quadros } \\
\text { interativos, sistemas de e-learning) em escolas públicas }\end{array}$ \\
\hline & $\begin{array}{l}\text { Gestão do } \\
\text { capital } \\
\text { humano }\end{array}$ & $\begin{array}{l}\text { Políticas para melhorar o investimento em capital humano com a } \\
\text { finalidade de atrair e reter novos talentos. }\end{array}$ \\
\hline
\end{tabular}

Fonte: Elaborado pelas autoras, com base na pesquisa de Neirotti et al., 2014

Além das categorias apresentadas, Cebreiros e Gulín (2014) mencionam a identidade do território como um elemento a ser explorado pelas iniciativas smart. A 
identidade do território pode ser um fator competitivo e de coesão social em função de sua contribuição em relação ao envolvimento positivo das pessoas com a cidade. Os autores também apontam a capacidade de alcançar e inspirar um sentimento de identidade, orgulho, pertencimento e solidariedade.

Os benefícios dessas iniciativas possivelmente repercutem nas outras categorias, uma vez que se promove a equidade e a coesão social, ou seja, os cidadãos passam a respeitar e valorizar os equipamentos, espaços e serviços de uso coletivo. A partir das categorias e subcategorias apresentadas, o tópico a seguir busca discutir as possibilidades de contribuição do Design para a SC.

\section{AS CONTRIBUICÕES DA GESTÃO DE DESIGN PARA A SC}

A gestão de design pode contribuir com a transformação da sociedade, a partir da utilização das competências da empresa ou instituição relacionada ao design para as cidades em interpretar as necessidades materiais e comportamentais dos indivíduos. As necessidades podem ser atendidas a partir de diversas disciplinas do design.

Segundo Mozota (2011), há quatro tipos de design que compreendem os principais domínios dos quais a profissão é integrada na sociedade, bem como as interfaces com diferentes funções perante as empresas: design de ambientes, design de produto, design de embalagens e design gráfico. Em uma classificação contemporânea considera-se essa grandes disciplinas e acrescentam-se o design para experiência, design de interação, design para a sustentabilidade, design para serviços, design para transformação (SANDERS; STAPPERS, 2008). Essas disciplinas são apenas alguns exemplos das possibilidades de atuação do designer, tendo em vista as crescentes especificidades da área: design de sistemas de informação e comunicação, design de mídias digitais, design de sinalização, design thinking, inovação orientada pelo design, design e emoção, design universal e design inclusivo, ergonomia e usabilidade, design centrado no usuário, sistema produto-serviço (PSS), design de superfície, design de interfaces, design colaborativo, entre outros (P\&D, 2014).

Buscou-se, a partir de experiências e iniciativas com características smart, que estão sendo desenvolvidas no Brasil e em outros países, relacioná-las com as possibilidades de atuação do designer. As relações foram estabelecidas com base em interpretações, análises, associações empíricas e reflexões efetuadas pelas autoras considerando as competências, habilidades e conhecimentos atribuídos aos designers.

Ressalta-se que o intuito em apontar proposições de atuação ou contribuição do design à SC é, apenas, de ilustrar algumas possibilidade. Portanto, não pretende-se reduzir ou exaurir tais possibilidades, mesmo porque não contempla-se todas as disciplinas do design em cada categoria. A contribuição destes apontamentos está em ampliar as discussões sobre as inter-relações entre design e SC. Para tanto, o Quadro 3, cita alguns exemplos de intervenção do design em cada categoria. 
Quadro 3 - Inter-relação entre gestão de design e SC

\section{Categoria e subcategorias de atuação: Recursos naturais e energia}

\begin{tabular}{|c|c|}
\hline \multirow[t]{2}{*}{ Smat Grids } & $\begin{array}{l}\text { Propor produtos que reaproveitem ou gerem energia para outros produtos, sistemas e/ou } \\
\text { habitações. Desenvolvimento de interfaces e ambientes dos centros de controle operacional de } \\
\text { gestão dos recursos. Desenvolver interfaces ou aplicativos que sejam utilizados como meios de } \\
\text { comunicação a fim de informar o usuário sobre os horários de tarifas reduzidas para consumo de } \\
\text { energia. Desenvolver meios de transporte elétrico ou que utilizem energia renovável. } \\
\text { Desenvolver contadores inteligentes de energia para habitações, afim de que os usuários } \\
\text { monitorem o consumo. Desenvolver etiquetas de comunicação sobre a eficiência energética de } \\
\text { produtos. A partir de soluções espontâneas desenvolvidas pela população, conhecidas como } \\
\text { gambiarras, identificar oportunidades de desenvolvimento de produtos que busquem a geração } \\
\text { de energia, ou práticas adotadas para economia. }\end{array}$ \\
\hline & Iniciativas e projetos utilizados como referência: Smartcity Málaga, InovCity Évora, e-DASH. \\
\hline \multirow[t]{2}{*}{$\begin{array}{l}\text { lluminação } \\
\text { pública }\end{array}$} & $\begin{array}{l}\text { Propor artefatos de iluminação pública ou que possuam outras funções smarts (multi-função), } \\
\text { como por exemplo monitoramento de tráfego ou câmeras de segurança. Optar pela aplicação } \\
\text { materiais, tintas, entre outros que possuam tecnologias incorporadas, como por exemplo, a } \\
\text { aplicação de tinta reflexiva em superfícies de sinalização viária. A tinta absorve o calor da energia } \\
\text { solar e durante a noite reflete a energia acumulada durante o dia. }\end{array}$ \\
\hline & $\begin{array}{l}\text { Iniciativas e projetos utilizados como referência: Projetto Lumière, Smart highway (Studio } \\
\text { Roosegaarde), Intellistreets. }\end{array}$ \\
\hline \multirow[t]{2}{*}{$\begin{array}{l}\text { Energia } \\
\text { renovável }\end{array}$} & $\begin{array}{l}\text { Desenvolvimento de produtos, serviços e sistemas que promovam o consumo sustentável dos } \\
\text { recursos através de intervenções tecnológicas que buscam orientar, manter ou modificar o } \\
\text { hábito de consumo do usuário. Esta abordagem é denominada Design para o Comportamento } \\
\text { Sustentável (DfBS) (LILEY et al.,, 2011, DAROS, 2012). Desenvolvimento de dispositivos, } \\
\text { equipamentos, eletrodomésticos, veículos elétricos que incorporem soluções como painéis } \\
\text { solares e fotovoltaicos, energia eólica. a partir de soluções espontâneas desenvolvidas pela } \\
\text { população, identificar oportunidades de desenvolvimento de produtos que utilizem a pedalada } \\
\text { assistida (DAROS, 2012) }\end{array}$ \\
\hline & $\begin{array}{l}\text { Iniciativas e projetos utilizados como referência: Design-Behaviour.co, e-wise e LED (Núcleo de } \\
\text { Design e Sustentabilidade da Universidade Federal do Paraná - NDS/UFPR) }\end{array}$ \\
\hline \multirow[t]{2}{*}{$\begin{array}{l}\text { Gestão de } \\
\text { resíduos }\end{array}$} & $\begin{array}{l}\text { Elaborar material didático, material gráfico para campanhas de conscientização e educação } \\
\text { ambiental, como por exemplo coleta seletiva, destarte correto de materiais tóxicos, incentivo a } \\
\text { compostagem. Desenvolvimento de produtos com mecanismos de monitoramento sobre o } \\
\text { comportamento das pessoas, em diferentes ambientes, ou nas diferentes etapas dos processos } \\
\text { de gestão de resíduos, em relação à produção e reciclagem de resíduos. Desenvolvimento de } \\
\text { artefatos (lixeiras, sacolas) que utilizem os conceitos do design sustentável. Desenvolver vídeos } \\
\text { e/ou jogos para smartphones para envolver as pessoas nos processos de reciclagem. Desenvolver } \\
\text { projetos junto à cooperativas populares de reciclagem. Desenvolver blogs, portais, sites que } \\
\text { mostre os pontos de descarte e doação para óleo de cozinha, medicamentos. Desenvolver } \\
\text { projeto de composteiras residenciais. }\end{array}$ \\
\hline & $\begin{array}{l}\text { Iniciativas e projetos utilizados como referência: Green Play, Cartão Groningen, Bin Bin (formato } \\
\text { verde), Ecycle, Descarte Consciente, Desapego Consciente, Programa Recicle Log, Rota da } \\
\text { Reciclagem, Freecycle, Curso de compostagem residencial Escritório Verde UTFPR (Universidade } \\
\text { tecnológica Federal do Paraná), Jogada certa UTFPR. }\end{array}$ \\
\hline \multirow[t]{2}{*}{$\begin{array}{l}\text { Gestão da } \\
\text { água }\end{array}$} & $\begin{array}{l}\text { Desenvolvimento de dispositivos e sensores que coletam e processam informações sobre } \\
\text { qualidade da água, localização de fugas e acionam alertas, bem como a elaboração dos projetos } \\
\text { das interfaces e os meios de disponibilização destas informações. Projeto do conjunto de } \\
\text { artefatos que compõem as redes de captação, abastecimento, distribuição e tratamento de } \\
\text { água. Desenvolvimento de interfaces dos softwares utilizados para processamento de dados da } \\
\text { gestão da água, bem como os ambientes dos centros de controle operacional de gestão dos } \\
\text { recursos. Elaboração dos relatórios em mídia impressa e digital. }\end{array}$ \\
\hline & $\begin{array}{l}\text { Iniciativas e projetos utilizados como referência: Plano de reutilização de águas de Madri, e- } \\
\text { harbours eletric, Centro de controle operacional das águas de Santiago - Chile, Smart Metering, } \\
\text { Vitoria Gasteiz, e-wise e LED (NDS/UFPR) }\end{array}$ \\
\hline \multirow[t]{2}{*}{$\begin{array}{l}\text { Alimentação e } \\
\text { agricultura }\end{array}$} & $\begin{array}{l}\text { Desenvolvimento de dispositivos e sensores que informam temperatura, umidade, condições } \\
\text { climáticas para os próximos dias acessíveis aos agricultores. Desenvolvimento de interface para } \\
\text { plataforma web de gestão. Desenvolvimento de artefatos, ferramentas e maquinários. } \\
\text { Elaboração de site e material voltado à mídias sociais, material didático, material de } \\
\text { comunicação e divulgação. }\end{array}$ \\
\hline & $\begin{array}{l}\text { Iniciativas e projetos utilizados como referência: Food Sharing, Slow Food, Horta urbana (oficina } \\
\text { escritório verde UTFPR, CSA Brasil, VITIC, Estratégia Alimentar de Toronto (TFPC). }\end{array}$ \\
\hline
\end{tabular}




\begin{tabular}{|c|c|}
\hline \multicolumn{2}{|c|}{ Categoria e subcategorias de atuação: Transporte e mobilidade } \\
\hline $\begin{array}{l}\text { Logística da } \\
\text { cidade }\end{array}$ & $\begin{array}{l}\text { Desenvolver mapas de fluxos logísticos. Dispositivos e sistemas de comunicação e informação } \\
\text { sobre as condições de tráfego. }\end{array}$ \\
\hline $\begin{array}{l}\text { Informações } \\
\text { de mobilidade }\end{array}$ & Interfaces para diversos dispositivos digitais. \\
\hline \multirow[t]{2}{*}{$\begin{array}{l}\text { Mobilidade de } \\
\text { pessoas }\end{array}$} & $\begin{array}{l}\text { Projetos de sinalização de terminais de ônibus, estações de metrô, taxi, mapas dos itinerários, } \\
\text { soluções em mobilidade elétrica, desenvolvimento de sistemas informação e/ou serviços } \\
\text { multimodais ou de uso compartilhado, mobiliário urbano (bancos, proteção para pontos de } \\
\text { ônibus, bike share, etc). Materiais de divulgação. Interface de aplicativos, sistemas de informação } \\
\text { e mídias digitais para aluguel ou compartilhamento de carro, bicicleta, etc. Projetar sistemas de } \\
\text { mobilidade inclusivo, compreendendo o desenvolvimento de calçadas e superfícies à meios de } \\
\text { transporte. }\end{array}$ \\
\hline & $\begin{array}{l}\text { Iniciativas e projetos utilizados como referência: First Orientations on Automated Modes of } \\
\text { Transport (FOAM), EMORAIL. Compartilhamento de automóveis: LOGeco, LabCityCar, Zipcar, } \\
\text { Street car, Flexi Car, Go-Get, Cityhop, Mu (Peugeot), HourCar, Connect by Hrtz, BMW Brive Now, } \\
\text { WhipCar, RelayRides, Spride, Getaround, Drivemycarrentals. Compartilhamento de bicicletas: } \\
\text { Velib, B-Cycle, Bixi, Barclays, SmartBike, Malbourne Bike Share, Bicincitta, Samba, Mobilicidade, } \\
\text { Zilok, Rentoid, HireThings, Ecomodo, Thingloop, Rentalic, Terracycle, entre outros }\end{array}$ \\
\hline \multicolumn{2}{|c|}{ Categoria e subcategoria de atuação: Edifícios } \\
\hline $\begin{array}{l}\text { Gestão de } \\
\text { instalação }\end{array}$ & Manuais de instrução para instalação, limpeza, manutenção. \\
\hline Serviços & $\begin{array}{l}\text { Desenvolver produtos que atendam a infraestrutura das construções, como por exemplo: } \\
\text { elevadores, escadas rolantes, contadores de energia e água, entre outros. Desenvolver sistemas } \\
\text { de comunicação e informação para estes equipamentos. }\end{array}$ \\
\hline \multirow[t]{2}{*}{$\begin{array}{l}\text { Qualidade da } \\
\text { edificação }\end{array}$} & $\begin{array}{l}\text { Propor produtos, dispositivos ou sistemas de ventilação e iluminação com maior eficiência e } \\
\text { conforto lumínico e/ou térmico. Propor produtos e sistemas de captação e reuso da água. Propor } \\
\text { produtos e sistemas para geração e distribuição de energia. }\end{array}$ \\
\hline & $\begin{array}{l}\text { Iniciativas e projetos utilizados como referência RE:FIT, Escritório Verde UTFPR, Bilbao Kirolak, } \\
\text { Smart Student Units }\end{array}$ \\
\hline \multicolumn{2}{|c|}{ Categoria e subcategorias de atuação: Vida / Convivência } \\
\hline \multirow[t]{2}{*}{$\begin{array}{l}\text { Entretenimen- } \\
\text { to }\end{array}$} & $\begin{array}{l}\text { Interface de aplicativos que fomentem encontros em praças públicas. Projetar brinquedos, } \\
\text { equipamentos de ginástica a serem disponibilizados em espaços abertos e públicos. }\end{array}$ \\
\hline & Iniciativas e projetos utilizados como referência: Rolezinho, \\
\hline \multirow[t]{2}{*}{ Hospitalidade } & $\begin{array}{l}\text { Desenvolver displays e stands para informações turísticas. Desenvolver sistemas de identidade } \\
\text { visual para cidade. Desenvolver materiais de comunicação impressos, digitais, aplicativos, } \\
\text { realidade aumentada para divulgação e informação dos pontos turísticos. Desenvolver sistemas } \\
\text { de comunicação e informação sobre os impactos ambientais do turismo. }\end{array}$ \\
\hline & $\begin{array}{l}\text { Iniciativas e projetos utilizados como referência: Bordéus Realidade Aumentada, Talking } \\
\text { Heritage (Parque de Sintra), Astorga Smart City, }\end{array}$ \\
\hline \multirow[t]{2}{*}{$\begin{array}{l}\text { Controle de } \\
\text { poluição }\end{array}$} & $\begin{array}{l}\text { Desenvolver dispositivos e sensores para controle da poluição. Desenvolver interfaces para sites. } \\
\text { Relatórios sobre a emissão de } \mathrm{CO} 2 \text {. Desenvolvimento de artefatos, como por exemplo bicicletas } \\
\text { cujas rodas possuem sensores que detectam os níveis de poluição acústica e atmosférica de } \\
\text { diversos pontos da cidade. Esses dados ficam disponíveis para upload. }\end{array}$ \\
\hline & Iniciativas e projetos utilizados como referência: Copenhaguen Wheel, \\
\hline \multirow[t]{2}{*}{$\begin{array}{l}\text { Segurança } \\
\text { pública }\end{array}$} & $\begin{array}{l}\text { Desenvolver dispositivos, sensores, câmeras, veículos inteligentes, entre outros. Interfaces para } \\
\text { sistemas de vigilância e monitoramento. Projeto do serviço de segurança pública propriamente } \\
\text { dito. Projetar o serviço de atendimento dos centros de emergência: polícias e bombeiros. }\end{array}$ \\
\hline & $\begin{array}{l}\text { Iniciativas e projetos utilizados como referência: Buenos Aires Cidade Segura (BACS), Safe City } \\
\text { Camera Program Melbourne, Sistemas de sirenes e apitos adotas por alguns bairros em Curitiba. }\end{array}$ \\
\hline \multirow[t]{2}{*}{ Saúde } & $\begin{array}{l}\text { Desenvolver interfaces para aplicativos e sites que ensinem técnicas de relaxamento, psicologia } \\
\text { positiva, disponibilize informações sobre alimentação, nutrição, a melhora da qualidade de vida } \\
\text { e o bem-estar psicológico. Sinalização de ambientes hospitalares e postos de saúde. Mobiliário } \\
\text { hospitalar. Embalagens, bulas e rótulos para medicamentos. Desenvolver sistema de identidade } \\
\text { visual. Projetar os instrumentos cirúrgicos e equipamentos hospitalares. Projetar o serviço de } \\
\text { hospitais e postos de saúde. Desenvolver serviços e artefatos que compõem a infraestrutura } \\
\text { física e social atendendo os princípios do design inclusivo, ergonomia e usabilidade. Desenvolver } \\
\text { produtos, serviços e sistemas que apoiem a novas tecnologias como a telemedicina, a } \\
\text { teleassistência, módulos móveis. }\end{array}$ \\
\hline & $\begin{array}{l}\text { Iniciativas e projetos utilizados como referência: Health-Lab Amsterdam, Global Age-Friendly } \\
\text { Cities, A City for All Ages (ACFAA), Teleassistência Taipé, Tele-alarme Le Havre, Mayordomo, } \\
\text { Smith Country Memorial Hospital (smithcohosp), }\end{array}$ \\
\hline
\end{tabular}




\begin{tabular}{|c|c|}
\hline \multirow[t]{2}{*}{$\begin{array}{l}\text { Bem estar e } \\
\text { inclusão social }\end{array}$} & $\begin{array}{l}\text { Desenvolver a interface de aplicativos ou layouts para redes sociais que disponibilize ao cidadão } \\
\text { as principais informações das atividades urbanas na localidade em que este esteja, para } \\
\text { tomadas de decisão. Projetar espaços e serviços para melhor aproveitamento de atividades } \\
\text { sociais. Site colaborativo que permite comparar o custo de vida entre cidades. }\end{array}$ \\
\hline & $\begin{array}{l}\text { Iniciativas e projetos utilizados como referência: Live Singapore, Smart Citizen, Cidade } 2020 \\
\text { (innprontaciudade2010), Expatistan (cost of living), }\end{array}$ \\
\hline \multirow[t]{2}{*}{ Cultura } & $\begin{array}{l}\text { Propor projetos e soluções que envolvam a melhoria da atratividade e exploração do patrimônio } \\
\text { cultural da cidade. Desenvolver sistemas de compartilhamento, trocas e aluguel de filmes, } \\
\text { brinquedos e livros. }\end{array}$ \\
\hline & $\begin{array}{l}\text { Iniciativas e projetos utilizados como referência: Virada Cultural de Curitiba e São Paulo, Netflix, } \\
\text { Lend Around, Quickflix, Bigpond, DVD online Rental, Love Films, Zookal, Chegg, Text book } \\
\text { Exchange, read mooch, read it swap it, paper backswao, Toy Swap, Mums wap, Thered UP. }\end{array}$ \\
\hline \multicolumn{2}{|c|}{ Categoria e subcategorias de atuação: Governança } \\
\hline \multirow[t]{2}{*}{ E-government } & $\begin{array}{l}\text { Projetar serviços com base nos dados fornecidos pelo governo. Desenvolver proostas } \\
\text { inovadoras, a partir de do design colaborativo, para melhoria da sustentabilidade ambiental. } \\
\text { Oferecer suporte para ações de cidadania, como por exemplo materiais de divulgação, projeto } \\
\text { de ambientes para atendimento ao cidadão, entre outros. }\end{array}$ \\
\hline & $\begin{array}{l}\text { Iniciativas e projetos utilizados como referência: Open Data Euskadi, Open Data Lab Gijon, } \\
\text { Lombardia Open data, Helsinki Region Infoshare (HRI), Apps for Amsterdam, Manchester Digital } \\
\text { Development Agency (dda), Smart Barcelona, eVidens }\end{array}$ \\
\hline \multirow[t]{2}{*}{ E-democracia } & $\begin{array}{l}\text { Projetar sistemas, serviços, aplicativos e sites que o cidadão possa requerer serviços, avaliar o } \\
\text { funcionamento da cidade, por exemplo. Projetar os formulários administrativos, disponibilizar } \\
\text { informações sobre a vida na cidade, projetar plataformas participativas sobre temas } \\
\text { relacionados à cidade. }\end{array}$ \\
\hline & $\begin{array}{l}\text { Iniciativas e projetos utilizados como referência: Boston About Results (BAR - city of Boston), } \\
156 \text { Prefeitura Municipal de Curitiba/PR, Eu quero ajudar Curitiba, }\end{array}$ \\
\hline \multirow[t]{2}{*}{$\begin{array}{l}\text { Aquisição / } \\
\text { Transparência }\end{array}$} & $\begin{array}{l}\text { Desenvolver plataformas e sites que permitam o cidadão opinar sobre a gestão do orçamento } \\
\text { municipal, determinar as prioridades e projetos futuros. Desenvolver relatórios que contemplem } \\
\text { informações recolhidas de redes sociais e internet. }\end{array}$ \\
\hline & Iniciativas e projetos utilizados como referência: CM Cascais, SeeClickFix, Smart Santander, \\
\hline \multicolumn{2}{|c|}{ Categoria e subcategorias de atuação: Economia e pessoas } \\
\hline \multirow[t]{2}{*}{$\begin{array}{l}\text { Inovação e } \\
\text { empreendedor } \\
\text { ismo }\end{array}$} & $\begin{array}{l}\text { Desenvolver estratégias e plataformas participativas para que a comunidade expresse seus } \\
\text { interesses, necessidades e desejos. Projetar o serviço de apoio às incubadoras, micro, pequenas } \\
\text { e médias empresas. Apoiar com projetos e ações de design às redes e cooperativas que se } \\
\text { fundamentam na economia criativa e economia solidária. Desenvolver produtos e serviços } \\
\text { fundamentados nos conceitos de design sustentável, a fim de reduzir o consumo de energia, } \\
\text { água e matérias-primas. Desenvolver produtos a partir de resíduos e subprodutos. }\end{array}$ \\
\hline & $\begin{array}{l}\text { Iniciativas e projetos utilizados como referência: Bristolrising, Incubadora Lisboa, Made in } \\
\text { Saragoca, Kalundborg, Roterdão/Delta (PortoFrotterdam), }\end{array}$ \\
\hline \multirow[t]{2}{*}{$\begin{array}{l}\text { Gestão do } \\
\text { patrimônio } \\
\text { cultural }\end{array}$} & $\begin{array}{l}\text { Desenvolver projetos de revitalização de propriedades comerciais vazias, tornando-as } \\
\text { temporariamente acessíveis para usos comunitários ou para desenvolvimento de projetos } \\
\text { pontuais. }\end{array}$ \\
\hline & Iniciativas e projetos utilizados como referência: 3Space, \\
\hline \multirow[t]{2}{*}{$\begin{array}{l}\text { Educação } \\
\text { digital }\end{array}$} & $\begin{array}{l}\text { Projetar o material didático e de treinamento para projetos de alfabetização e capacitação digital } \\
\text { presencial e de educação a distância }\end{array}$ \\
\hline & $\begin{array}{l}\text { Iniciativas e projetos utilizados como referência: Plano de alfabetização digital do Ayuntamiento } \\
\text { de Barcelona, North West Minnesota Special Acess (nwmnsa), }\end{array}$ \\
\hline \multirow{2}{*}{$\begin{array}{l}\text { Gestão do } \\
\text { capital } \\
\text { humano }\end{array}$} & $\begin{array}{l}\text { Desenvolvimento de materiais impressos e digitais para capacitação, bem como plataformas e } \\
\text { sites. }\end{array}$ \\
\hline & Iniciativas e projetos utilizados como referência \\
\hline \multicolumn{2}{|c|}{ Categoria e subcategorias de atuação: Marca cidade e coesão social } \\
\hline \multirow[t]{2}{*}{$\begin{array}{l}\text { Marca cidade / } \\
\text { Coesão social }\end{array}$} & $\begin{array}{l}\text { Elaboração da identidade visual da cidade, em campanhas que valorizem aspectos locais (pontos } \\
\text { turísticos, diversidade, cultura e tradição) ou que pretendem melhorar a imagem da cidade. } \\
\text { Projetar materiais de divulgação de encontros, atividades em comunidade }\end{array}$ \\
\hline & $\begin{array}{l}\text { Iniciativas e projetos utilizados como referência: Amsterdam Partners, Austin (EUA), Colombia é } \\
\text { Paixão, Civic Crowd, Play Streets for All, Smart City Valhadolid e Palencia (Smart City VyP), }\end{array}$ \\
\hline
\end{tabular}

Fonte: Elaborado pelas autoras.

Como pode ser observado, há diversas possibilidades de atuação do Design para a SC. Algumas modalidades do campo do design, como design gráfico, design de interfaces e design de produto, são mais conhecidas e, portanto, mais facilmente 
aplicadas. Já as modalidades do design que ainda apresentam-se como novidade aos gestores públicos e sociedade, necessitam ser discutidas a fim de encontrar meios para disseminação das atribuições e o perfil profissional do designer.

\section{CONCLUSÃO}

Este artigo buscou, através da revisão integrativa de literatura, elucidar os conceitos de SC, bem como as principais categorias e subcategorias de aplicação para SC, sendo classificadas em dois grupos rígidas e flexíveis. Cada categoria foi elencada com a atividade projetual de design a fim de exemplificar as possibilidades de atuação deste profissional.

Conclui-se que apesar de não ter encontrado um conceito amplamente aceito para SC, entende-se que estas são cidades que buscam soluções para os seus problemas visando a melhoria da qualidade de vida da população. A característica principal é o uso de TICs e TS, em maior ou menor grau, a fim de apoiarem o desenvolvimento de projetos e iniciativas.

Neste sentido, a gestão de design pode contribuir com o desenvolvimento de produtos, serviços e sistemas baseados tanto na inovação tecnológica quanto na inovação social. Entende-se que as soluções de característica smart estão inseridas em contextos complexos, onde une-se esforços entre governos, iniciativa privada, academia e sociedade para que as proposições possam retornar em forma de benefícios que melhorem a qualidade dos serviços e do bem-estar social. Portanto, o designer atuará de forma colaborativa, inserido em equipes multidisciplinares.

Embora, ainda, não se comprove a melhora da qualidade de vida da população por tais iniciativas, acredita-se que estas tendem a promover uma mudança na governança, pois a sociedade atua de forma mais participativa. Com estas novas possibilidades, a forma de exercer a gestão pública deve ser modificada, a tomada de decisão para desenvolvimento de projetos e ações públicas poderão ser mais assertivas, e assim atender com maior satisfação os anseios e necessidades da população.

\section{REFERÊNCIAS}

BOYKO, C.T. et al. Adressing sustainability early in the urban design process. Management of Environmental Quality. Bradford, v.17, no6, p. 689-706, 2006.

CARAGLIU, A., DEL BO, C.; NIJKAMP, P. Smart Cities in Europe. In 3rd Central European conference in regional science - CERS 2009, 7-9 October Košice, Slovak Republic. 2009.

CEBREIROS, Jorge; GULÍN, Marcos Pérez. Guia Smart Cities “Cidades com Futuro": agenda digital local Galicia-Norte Portugal. Eixo Atlântico do Noroeste Península: 2014.

CORDEIRO, A. M; OLIVEIRA, G. M; RENTERÍA, J. M; GUIMARÃES C. A. Revisão sistemática: uma revisão narrativa. Grupo de Estudo de Revisão Sistemática do Rio de Janeiro (GERS-Rio). Rev. Col. Bras. Cir. Vol. 34 - № 6, Nov/Dez 2007.

CORREIA, L. M., WÜNSTEL, K. Smart Cities applications and requirements. White Paper of the Experts Working Group, Net!Works European Technology Platform. 2011 <http://www.scribd.com/doc/87944173/White-Paper-Smart-Cities- Applications> Accessado em $10 / 04 / 2014$

DAROS, Carolina. Design para a sustentabilidade: oportunidades de inovaçãoo a partir dos hábitos de consumo na habitação de interesse social. 2013. 182 f. Dissertação (mestrado) - Universidade Federal do Paraná, Curso de Pós Graduação em Design.

FREEMAN, C. PEREZ, C. Structural crises of adjustment: business cycles, 1988. 
GALVÃO, C. M, SAWADA N. O., TREVIZAN M. A. Revisão sistemática: recurso que proporciona a incorporação das evidências na prática da enfermagem. Rev Latino- am Enfermagem 2004 Mai-Jun; 12(3):549-56

GIFFINGER, R., FERTNER, C., KRAMAR, H., KALASEK, R., PICHLER-MILANOVIC', N., MEIJERS, E. Smart Cities: Ranking of European medium-sized cities. Vienna, Austria: Centre of Regional Science (SRF), Vienna University of Technology. 2007 <http:// ww.smartcities.eu/download/smart_cities_final_report.pdf> Accessado 10/04/2014

HARRISON, C.; DONNELLY, I. A. A theory of smart cities. White Paper, IBM Corporation, 2011. Disponível em http://journals.isss.org/index.php/proceedings55th/article/ viewFile/1703/572. Acesso em $15 / 04 / 2014$

Hollands, R. G. Will the real smart city please stand up? Intelligent, progressive or entrepreneurial? City, 12(3), 303-319, 2008.

LEITE, Carlos. Cidades sustentáveis, cidades inteligentes [recurso eletrônico]: desenvolvimento sustentável num planeta urbanograduação e pós-graduação. Canoas: Salles, 2004.

MANZINI, E. Design para a inovação social e sustentabilidade: Comunidades criativas, organizações colaborativas e novas redes projetuais. 2009.

MENDES, K. D. S; SILVEIRA, R. C. C. P; GALVÃO, C. M. Revisão integrativa: método de pesquisa para incorporação de evidências na saúde e na enfermagem. Texto \& Contexto Enfermagem [on line]; vol. 17, no. 4, p. 758-764; 2008. Disponível em: <http://www.scielo.br/pdf/tce/v17n4/ 18.pdf>. Acesso em: 06/05/2014.

McAfee, A., \& Brynjolfsson, E. (2012). Big Data's Management revolution. Harward Business Review.

McKinsey Global Institute (2011). Big Data: The next frontier for innovation, competition and productivity $\quad<$ http://www.mckinsey.com/insights business_technology/big_data_the_next_frontier_for_innovation> Acessado em 23/04/2014.

OCDE - Organização para a Cooperacão e Desenvolvimento Econômico Territorial Reviews: Competitive Cities in the Global Economy. 2012

ONU - HABITAT. Estado de Las Ciudades de América Latina Y El Caribe 2012: Rumbo a una nueva transición urbana. Programa de las Naciones Unidas para las Asentamientos Humanos. Agosto, 2012.

RASOOLIMANESH, S.M.; BADARULZAMAN, N.; JAAFAR, M. Achievement to Sustainable Urban Development using City Development Strategies: A Comparison between Cities Alliance and the World Bank definitions. Journal of Sustainable Development, v. 4, n. 5, p. 151-166, 2011.

SCHUMPETER, J.A. Teoria do Desenvolvimento econômico: uma investigação sobre lucros, capital, crédito, juro e o ciclo econômico. Círculo do Livro - São Paulo, 1999.

TOPPETA, D. The Smart City vision: How Innovation and ICT can build smart, "liveable", sustainable cities. The Innovation Knowledge Foundation. Think!Report, 005/2010. Disponível em http://www.thinkinnovation.org/file/research/23/en/Toppeta_Report_005_2010.pdf. Acesso em $15 / 03 / 2014$

WEISS, Cesar Marcos; BERNARDES, Roberto Carlos; CONSONI, Flavia Luciane. Cidades inteligentes: casos e perspectivas para as cidades brasileiras. http://www.altec2013.org/programme_pdf/1511.pdf. Acessado em: 03/03/2014. 